\title{
Reducing behavioral health symptoms by addressing minority stressors in LGBTQ adolescents: a randomized controlled trial of Proud \& Empowered
}

Jeremy T. Goldbach ${ }^{1 *}$ (D), Harmony Rhoades², Mary Rose Mamey², John Senese ${ }^{2}$, Peter Karys ${ }^{3}$ and Flavio F. Marsiglia ${ }^{4}$

\begin{abstract}
Background: Minority stress may lead to poorer mental health for sexual and gender minority adolescents, yet no interventions have been tested through an RCT to address these concerns.

Methods: We report on an RCT of an intervention—Proud \& Empowered—with four high schools. Measures assess the intervention's impact on mental health symptoms.

Results: Compared to the control, participants in the treatment condition reported significant differences in minority stress, anxiety, and depressive symptoms. Moderation analyses showed that the intervention significantly moderated the relationship between minority stress and PTSD $(b=-1.28, p=.032)$, depression $(b=-0.79, p=.023)$, and suicidality $(b=0.14, p=.012)$ symptoms; those in the intervention condition had mitigated relationships between measures of stress and health outcomes compared to those in the control condition.
\end{abstract}

Conclusions: Results suggest that Proud \& Empowered help reduce mental health symptoms and exposure to minority stressors and build coping strategies.

Trial Registration: The intervention was registered on clinicaltrials.gov on August 1, 2019 under Trial \#NCT04041414.

Keywords: LGBT, Adolescent, Mental health, Intervention, Randomized controlled trial

\section{Background}

Sexual and gender minority adolescents (SGMA; i.e., youth who identify as something other than heterosexual and those with a gender identity that does not align with their assigned sex at birth) endure numerous behavioral health symptoms and disparities when compared to their heterosexual, cisgender peers. These disparities include higher rates of internalizing psychopathology [1], such

\footnotetext{
${ }^{*}$ Correspondence: jgoldbach@wustl.edu

${ }^{1}$ The Brown School, Washington University in St. Louis, 1 Brookings Dr, MO 63130 St. Louis, USA

Full list of author information is available at the end of the article
}

as depression [2], anxiety [3], self-harm [4], and posttraumatic stress disorder (PTSD) symptomology [5], and externalizing behaviors such as substance use $[6,7]$ and suicide attempt and completion [8].

Minority stress theory explains these mental health disparities by suggesting that discrimination, violence, and victimization drives experiences of chronic minority stress $[9,10]$. The long-term nature of these stress experiences place SGMA, aged 12-25 years, at higher risk of mental health conditions [11-13]. Evidence for this relationship between minority stress and behavioral health $[11,12]$ is clear, and displayed through numerous cross-sectional studies, including experiences of violent 
victimization [14], homophobic bullying [15], and family rejection in adolescence $[11,12,16]$. Similarly, studies have identified sexual minority-specific victimization [17] and stress experiences [10, 18] as mediating the relationships between sexual identity status and depression, PTSD, and suicidality [18-20]. These studies come together to provide robust evidence that improving youths' ability to cope with minority stress is an important piece to improving mental health outcomes among SGMA, and that direct interventions are a means to fill this gap.

Despite a significant need to be addressed among SGMA, it has been noted that there are "no determinative studies, such as randomized control trials, of the efficacy and effectiveness of school based interventions [for SGMA]" (p.1767) [21], and the one U.S. based intervention with substantial quasi-experimental (the Family Acceptance Project [22]) relies heavily, on family participation. The challenge here is that many SGMA report not disclosing their sexual or gender identity to their family for fear of rejection [23], and those who do disclose their identity, often report a lack of family support [24, 25]. Another set of interventions developed in Canada, including Affirmative Supportive Safe and Empowering Talk and an affirmative behavioral coping skills group intervention [26, 27], as well as a Western Canadian media-based intervention to reduce bullying [28] have also found support, but their efficacy has yet to be established through randomized control designs in the literature. Thus, interventions that have a strong theoretical foundation, follow the National Institutes of Health's gold-standard phase model of intervention development and testing, and rely solely on individual choice without family involvement are an essential but missing part of psychoeducational work needed to help SGMA cope with minority stress [5]. To address this gap in the literature, we developed a novel program, Proud \& Empowered (P\&E), to be delivered in school or community-based settings.

\section{Development of Proud \& Empowered}

The P\&E intervention was named through a democratic vote by youth at LGBT centers after multiple rounds of development, implementation, and revision that followed the NIH Intervention Stage Model for Behavioral Intervention Development [29]. The 10-session small group intervention was supported by studies from 2012 to early 2020 , most notably the development of a comprehensive minority stress measure for adolescents, the Sexual Minority Adolescent Stress Inventory (SMASI) [30, 31]. Although more detailed information can be found elsewhere [31], the SMASI emerged from a multiphase mixed-methods study including key informant interviews and focus groups [5]; life history calendar interviews [32] with 52 racially, ethnically, and gender diverse SGMA aged 14-17; a modified Delphi process [33] with an advisory panel of six experts in SGMA, minority stress theory, and psychometric development; and a rigorous validation process with adolescents $(N=346)$, including factor analytic and item response theory approaches [31]. The final SMASI measure found 10 conceptual domains: social marginalization, family rejection, internalized homonegativity, identity management, homonegative climate, intersectionality, negative disclosure experiences, religion, negative expectancies, and homonegative communication.

Considering the correlation between high stress in each domain and poorer health, we posited that ameliorating these stressors for SGMA would improve their health outcomes. Thus, the SMASI domains formed the basis for P\&E's 10 intervention sessions. Through an iterative process, consensus was reached that the intervention should include content on (a) stress and coping [9]; (b) disclosure decision-making [34]; (c) family; (d) schoolrelated stress and resilience [35]; (e) peers and friendship [36]; (f) safety in relationships; (g) spirituality, faith, and religion [37]; (h) race, ethnicity, and social justice; (i) the LGBT community and history; and (j) intersections of health, substance use, HIV, and the medical system [38]. These aligned closely with the 10 SMASI domains and were agreed to by our research team, LGBT youth center staff, and the group of youth who participated in focus groups.

As intervention content was built, we also focused on understanding what strategies may be useful in coping for SGMA. Relying on the most commonly cited model of coping presented by Compas and colleagues [39], the study team identified both voluntary and involuntary physiological and emotional responses that may be related to SGMA minority stress, as well as engagement and disengagement strategies and coping resources with relevance to population health. In sum, we identified 16 population-specific coping resources that would further inform the intervention: for example, learning about the LGBTQ community, accessing factual historical information, or finding a supportive adult (ally). More detailed information on these novel coping resources is published elsewhere [5]. Finally, the intervention was pilot tested and further refined through a formative process with SGMA input, also published in a paper on the complete development process [40].

In sum, the final P\&E intervention is a 10-session small group program for SGMA, with each session lasting approximately $45 \mathrm{~min}$ (one class period). A facilitator manual guides the curriculum; is used to monitor fidelity; and includes goals, learning objectives, activities, and 
a list of materials used for each session. Sessions rely on a mix of psychoeducation, didactic discussion, and interactive (e.g., role-play) activities. Following the previously described studies, the present article reports on a randomized controlled trial conducted at four public schools on the west coast of the United States to examine the efficacy of the P\&E program. We hypothesized that youth who participated in P\&E would (a) report significantly fewer minority stress experiences postintervention than those in the control group and (b) report significantly improved behavioral health symptomology (i.e., depression, PTSD, anxiety, and suicidality) compared to youth in the control group. We also examined whether participation in P\&E moderated the relationship between minority stress and behavioral health symptoms to assess whether participation may improve youths' ability to cope with minority stressors when they arise, because eliminating them is unfeasible.

\section{Methods \\ Design}

The randomized controlled trial was approved by the lead author's institutional review board and was registered with clinicaltrials.gov. No major deviations occurred in the submitted protocol, and data collection for the intervention ended before COVID-19 resulted in school closures. The study was conducted with four schools in fall 2019 that collectively make up a unified school district in Southern California. The four schools' range in size from 902 to 1,971 students each, have a combined enrollment of 5,706, and represent diverse racial and ethnic (e.g., $60 \%$ identify as Hispanic or Latinx and $16 \%$ as Black or African American) and income (e.g., 26\% of families earn between $\$ 15,000$ and $\$ 49,000$ per year and $11 \%$ earn less than $\$ 15,000$ per year) groups. All four schools had an active gender and sexuality alliance (GSA), but identified no other programming. The schools were randomly assigned to either an intervention or control condition. Youth in the intervention condition participated in the 10 -week P\&E program during one class period per week, whereas youth in the control condition attended school as usual during the same time period. Youth in both conditions completed measures at pretest and posttest, and measures were administered during the same week to both study conditions (pretest was one week prior to the first scheduled intervention session and posttest was 1 week after the last intervention session). We intended to complete a subsequent post-test measure, but restrictions due to the COVID-19 pandemic prevented this from occurring. Measures included demographic characteristics, our hypothesized mechanisms of change (i.e., minority stress), and mental health symptoms (i.e., depression, anxiety, PTSD, and suicidality). Participants received a $\$ 20$ gift card for completing the measures at pretest and a $\$ 25$ gift card at posttest.

\section{Fidelity Monitoring}

Fidelity monitoring was conducted using an approach developed in our prior pilot work [40] and was focused on adherence to curriculum, dosage, quality of service delivery, participant responsiveness, and program differentiation. [41] After each session, the facilitator and the liaison (co-facilitator) rated the objectives, content, and activities on fidelity, appropriateness, and participant receptiveness using an adherence checklist. Based on the core dimensions of the cultural adaptation model, [42] liaisons were asked to identify cognitive (comprehension), affective (cultural conflicts or motivation issues), developmental, and any other problems (e.g., environmental) with activities and rate fidelity to each session element (concepts, objectives, activities, instructions).

\section{Participants}

Youth could participate in the P\&E study if they (a) were students at the high school; (b) spoke English; (c) self-identified as LGBT or other non-heterosexual or cisgender identity; and (d) were willing and able to provide verbal assent. To identify potential participants, the study coordinator and school counselors made verbal presentations, distributed fliers, and had direct and confidential meetings to recruit youth to the study. Because LGBT youth represent a sensitive population and human subjects' protection is complex (i.e., parents may not know their sexual or gender identity), we requested and received a waiver of parental consent by the institutional review board at the study team's institution. Thus, potential youth participants received a detailed information sheet outlining the study goals, objectives, benefits, and possible risks and provided verbal assent or consent to participate (if they were 18 years old or turned 18 during the study).

Both school facilitators and student participants were informed that their school would be randomly selected to serve as either an intervention or control site. The district was recruited at the superintendent level, staff members at all schools were trained, students were administered pretests, and then schools were randomly assigned. We followed this process to help reduce the potential for bias in procedures.

\section{Procedures \\ Facilitator training}

Although the intervention was led by a study team member, selected school staff members were trained to cofacilitate the curriculum to ensure the program could be readily administered by counselors, teachers, and other 
school personnel (e.g., social workers). Each school had up to two full-time staff members who received a 1-day training on the $P \& E$ curriculum overseen by the principal investigator and facilitated by the project coordinator. Most staff members were school counselors $(n=$ $5)$, but also included teachers $(n=2)$ and other trained staff members. The training covered topics including: (a) minority stress among adolescents, (b) adolescent development and gender and sexual identity formation, (c) the NIH prevention principles, (d) P\&E curriculum implementation, (e) fidelity monitoring processes, and (f) program outcomes and the research plan. Using previously established best practices [43], facilitators learned their roles in the project, identifying skills and concepts for each activity throughout the program. Facilitators received a $\$ 1,000$ honorarium for their time in the training and participation throughout the school year.

\section{Intervention condition}

Participants were organized to meet weekly during their administration period (i.e., homeroom), as part of their regular school day, to participate in the intervention. Each group was led by the project coordinator and a school staff member who had been trained as a facilitator. Each session covered a different domain of minority stress identified and refined in our prior work (as previously described). A facilitator manual guided the curriculum, was used to monitor fidelity, and included goals, learning objectives, activities, and a list of materials used for each session.

\section{Control condition}

Although we considered whether an attention control [44] would be helpful in establishing intervention effects and reducing bias, we ultimately determined that attending classes as usual would be the most appropriate alternative activity, given that it would most closely match what youth would do if their school did not offer a focused intervention. Therefore, participants in the control condition did not participate in any unique activities; rather, they completed the surveys on the same timeline, and with the same incentive procedures, as the intervention group.

\section{Measures}

\section{Demographic characteristics}

Demographic information was collected at both pre- and posttest and included gender, sex assigned at birth, age, grade, sexual orientation, and race. Gender categories included cisgender female, cisgender male, trans female or trans woman, trans male or trans man, and genderqueer or gender nonconforming. Sexual orientation had response options of gay, lesbian, bisexual, pansexual, asexual, and another sexual orientation (with the option to provide text). Participants could select all response options that applied on the race and ethnicity question, with options including non-Hispanic White, Black or African American, Latino or Hispanic, American Indian or Alaska Native, Native Hawaiian or other Pacific Islander, and another race and ethnicity with an openended text field. Other information collected included religion (both family and personal), language spoken (at home and with friends), whether the participant was currently working, and with whom the participant lives.

\section{Minority stress}

The SMASI features 54 items across 10 domains of minority stress for adolescents and demonstrates good reliability and validity in this population [30, 31]. Each statement reflects past-30-day thoughts, feelings, and situations a person may have experienced, with response options of $1=$ yes and $0=$ no. A decline-to-answer option was also provided. A total SMASI score was calculated by summing the 54 items. Mean imputation at the participant level was used for respondents missing fewer than seven items. Those missing seven or more items were removed from analysis. Scores for the 10 subscales were calculated using percentages; the number of endorsed (yes) responses were divided by the number of items a person actively responded to and multiplied by 100. The SMASI was collected at both time points.

\section{Anxiety}

Anxiety was measured using the 21-item Beck Anxiety Inventory [45]. Questions asked how much the person had been bothered by past-month symptoms, with response options of 0 (not at all), 1 (mildly but it didn't bother me much), 2 (moderately-it wasn't pleasant at times), and 3 (severely-it bothered me a lot). A sum score was created with a theoretical range between 0 and 63, with higher scores indicating higher levels of anxiety.

\section{Depression}

The Beck Depression Inventory II [46] is a list of 21 statements that describe how a person may have been feeling during the past 2 weeks, including sadness, loss of pleasure, and crying. Response options range from 0 to 3 and are unique to each question by catering to the specific feeling or behavior. Scores are calculated by summing all items and have a range between 0 and 63 . Higher scores on the inventory demonstrate higher levels of depression.

\section{PTSD}

The PTSD Checklist for DSM-5 [47] was used to measure PTSD and assessed the extent to which the participant was bothered by 20 past-month experiences. Response 
options range from 0 (not at all) to 4 (extremely), with a possible sum score range between 0 and 80 .

\section{Suicidality}

Suicidality was measured using the adapted ColumbiaSuicide Severity Rating Scale [48] through five yes-or-no questions pertaining to the past 30 days. Worst-point severity is used to score the measure; a person's last endorsed (yes) question is their score, with a range between 0 (no endorsed items) to 5 (a person endorsed the most severe question: "Have you thought about a specific plan [for example, having a time or place] to kill yourself?"). As a note, our human subjects plan included informing that if they endorsed suicidality, the facilitator would be informed confidentially (through Qualtrics skip logic) and that after class, they would be provided access to resources for dealing with suicidality, including an opportunity to speak privately with their school counselor to seek additional support. Eight participants endorsed suicidality at the pretest and received these resources.

\section{Intervention}

Each school was randomly assigned to the intervention or control condition. Thus, all students in a school received the same condition. Those in control schools were coded as 0 , and those in intervention schools were coded as 1 .

\section{Analysis}

Descriptive information for demographics and outcome measures were first reported. Preliminary analyses used chi-square tests and one-way analyses of variance (ANOVA) to ensure demographic information and SMASI and mental health outcomes did not differ by group assignment (intervention vs. control) at Time 1. A two-by-two (group by time) repeated-measures ANOVA was used to understand the relationship between preand posttests across the intervention conditions for each outcome of minority stress and its subscales, and mental health symptoms of anxiety, depression, PTSD, and suicidality. These were designed to determine whether the intervention group differed in outcomes from the control group over time.

Subsequent analyses examined intervention as a moderator of the relationship between minority stress and mental health symptoms at Time 2, while controlling for mental health symptoms at Time 1 . In each analysis, the mental health symptoms at Time 2 (dependent variable) were regressed onto the mental health symptoms at Time 1 (covariate), minority stress (independent variable), intervention (moderator), and the minority stress-intervention interaction term. Power analyses were conducted in G*Power 3.1.9.4 for both repeated-measures ANOVA and linear regressions with moderation. With 44 participants and $\alpha=0.05$, we were sufficiently powered (0.80) to detect an effect size of 0.12 for the repeated-measures ANOVA and an effect size of 0.18 for the moderation analysis. All analyses were conducted using SPSS version 25. Moderation analyses were conducted in the SPSS framework using PROCESS v. 3.4. [49].

\section{Results}

Of 46 students who actively participated in the study, two were removed for having not taken both the pre- and posttest (due to being absent at post-test). A consort diagram is provided below (Fig. 1).

Of the 44 participants retained for the study $(95.6 \%$ retention rate), 26 students (59.1\%) were in schools assigned to the intervention condition. Demographics are reported in Table 1. Chi-square tests were used to examine the relationship between group assignment and pretest demographic variables of interest. No significant differences were found between the intervention and control conditions for gender identity $\left(\chi^{2}=7.36\right.$, $p=.118)$, race $\left(\chi^{2}=0.47, p=.828\right)$, age $\left(\chi^{2}=6.04, p=\right.$ $.302)$, grade $\left(\chi^{2}=6.64, p=.084\right)$, and sexual orientation $\left(x^{2}=9.38, p=.153\right)$. Similarly, one-way ANOVAs were used to examine the relationship between group assignment and pretest outcome variables. No significant differences were found between minority stress total score $(F[1]=0.97, p=.330)$ or any of its subscales. Further, no significant differences were found between group assignment and mental health outcomes of anxiety $(F[1]=1.04$, $p=.315), \operatorname{PTSD}(F[1]=0.72, p=.402)$, depression $(F[1]$ $=0.55, p=.474)$, or suicidality $(F[1]=0.09, p=.764)$.

Repeated-measures ANOVAs for minority stress and mental health outcomes were conducted to assess differences in intervention groups across the two time points. A significant interaction effect was found for SMASI subscales of internalized homonegativity $(F[1]=5.28, p$ $=.028)$; the intervention condition decreased between Time $1(M=12.49, S D=17.71)$ and Time $2(M=4.16$, $S D=7.69)$, whereas the control condition increased between Time $1(M=3.30, S D=8.56)$ and Time $2(M=$ $7.69, S D=16.09$ ). Table 1 includes the means and standard deviations of the SMASI and its subscales. No significant findings were found for the SMASI total score, the other SMASI subscales, or the mental health outcomes. Means and standard deviations for SMASI and mental health outcomes can be found in Table 2 .

Analyses were further conducted to examine whether the intervention group moderated the association between minority stress and mental health symptoms. Minority stress had a statistically significant interaction with PTSD $(b=-1.29, p=.032)$; for those in the 


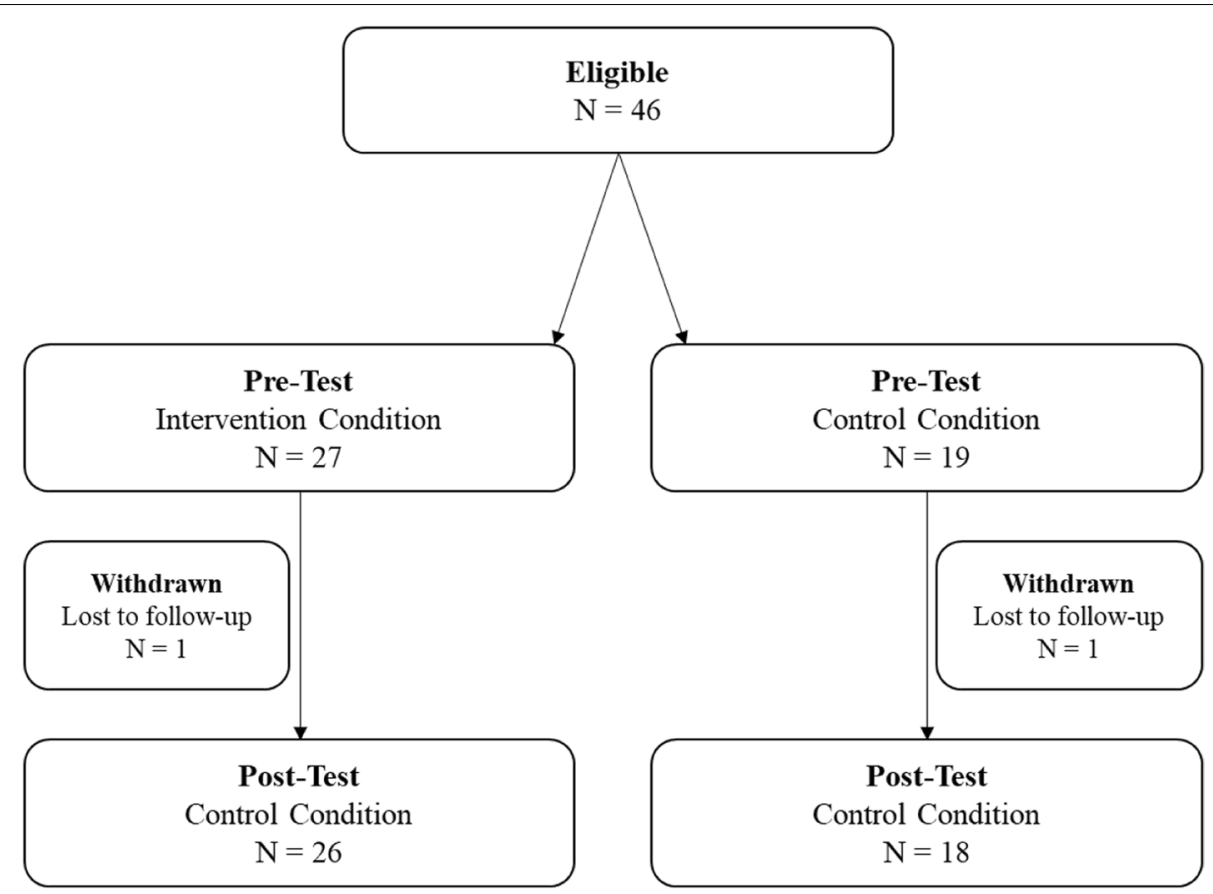

Fig. 1 Consort Diagram

intervention group, higher levels of minority stress were associated with lower levels of PTSD $(b=-0.48, p=$ .234), and for those in the control group, higher levels of minority stress were associated with higher levels of PTSD $(b=0.81, p=.063)$. This significant interaction suggests that the relationship between minority stress and PTSD differed between groups. Results also demonstrated a significant moderation effect of the intervention between minority stress and depression $(b=-0.79$, $p=.023)$. Higher levels of minority stress were associated with lower levels of depression for those in the intervention condition $(b=-0.36, p=.131)$, whereas higher levels of minority stress were associated with higher levels of depression for those in the control condition ( $b=0.43, p=.093)$. The intervention also significantly moderated the relationship between minority stress and suicidality ( $b=-0.14, p=.012)$; higher levels of minority stress were associated with lower levels of suicidality for the intervention condition $(b=-0.07, p$ $=.069$ ), and higher levels of minority stress were associated with higher levels of suicidality for the control condition ( $b=0.07, p=.087)$. Each of these findings show the intervention reduced the strength of the relationship between higher levels of minority stress and PTSD, depression, and suicidality when compared to the control condition. Table 3 reports these findings.

\section{Discussion}

This randomized controlled trial demonstrated evidence for the preliminary effectiveness of the P\&E prevention intervention. Because SGMA experience numerous mental health disparities when compared to their heterosexual peers, implementing interventions like P\&E may be crucial to promoting mental wellness and coping among these youth, who often manifest these experiences of minority stress as mental health symptomology throughout their lives [12, 30].

Supporting our first hypothesis, we found evidence that participation in the P\&E intervention reduced minority stress among intervention participants. Even with a sample of fewer than 50 youth across intervention and control conditions, we found statistically significant decreases in minority stress experiences among youth in the intervention group, whereas experiences of minority stress increased among those in the control condition. This suggests the intervention is successful in decreasing minority stress through reframing the understanding and approach of stressors in the control of participants. However, further research is needed with larger samples, because it was difficult to see changes in subscales of our minority stress measure, given sampling and power challenges.

As we also expected based on literature linking minority stress experiences with mental health [11, 
Table 1 Frequencies of Primary Demographics of 44 Adolescents

\begin{tabular}{|c|c|}
\hline & $n(\%)$ \\
\hline \multicolumn{2}{|l|}{ Group condition } \\
\hline Intervention & $26(59.1)$ \\
\hline Control & $18(40.9)$ \\
\hline \multicolumn{2}{|l|}{ Gender at birth } \\
\hline Female & $32(72.7)$ \\
\hline Male & $12(27.3)$ \\
\hline \multicolumn{2}{|l|}{ Gender identity } \\
\hline Female & $27(61.4)$ \\
\hline Male & $11(25.0)$ \\
\hline Trans female or trans woman & $1(2.3)$ \\
\hline Trans male or trans man & $2(4.5)$ \\
\hline Genderqueer or gender nonconforming & $3(6.8)$ \\
\hline \multicolumn{2}{|l|}{ Race (all that apply) } \\
\hline White & $15(33.1)$ \\
\hline Black or African American & $7(15.9)$ \\
\hline Latino or Hispanic & $24(54.5)$ \\
\hline Asian & $9(20.5)$ \\
\hline American Indian or Alaska Native & $1(2.3)$ \\
\hline Native Hawaiian or Pacific Islander & $1(2.3)$ \\
\hline \multicolumn{2}{|l|}{ Age } \\
\hline 13 years & $4(9.1)$ \\
\hline 14 years & $7(15.9)$ \\
\hline 15 years & $11(25.0)$ \\
\hline 16 years & $12(27.3)$ \\
\hline 17 years & $9(20.5)$ \\
\hline 18 years & $1(2.3)$ \\
\hline \multicolumn{2}{|l|}{ Grade } \\
\hline 9th grade & $8(18.2)$ \\
\hline 10th grade & $13(29.5)$ \\
\hline 11 th grade & $9(20.5)$ \\
\hline 12th grade & $14(31.8)$ \\
\hline \multicolumn{2}{|l|}{ Sexual orientation } \\
\hline Gay & $8(18.2)$ \\
\hline Lesbian & $6(13.6)$ \\
\hline Bisexual & $18(40.9)$ \\
\hline Pansexual & $5(11.4)$ \\
\hline Asexual & $2(4.5)$ \\
\hline Queer & $3(6.8)$ \\
\hline Straight & $1(2.3)$ \\
\hline Decline to answer & $1(2.3)$ \\
\hline
\end{tabular}

12], we found evidence suggesting that $P \& E$ reduces negative mental health symptoms (Hypothesis 2). Those in the intervention group reported decreased symptoms of anxiety and no change in depression symptoms, as compared to those in the control group, who saw no change in anxiety and an increase
Table 2 Past-30-day SMASI Scores and Health Outcomes of 44 Sexual Minority Youth

\begin{tabular}{lll}
\hline & Intervention & Control \\
& $\boldsymbol{M}(\boldsymbol{S D})$ & $\boldsymbol{M}(\boldsymbol{S D})$ \\
\hline Total T1 & $8.44(6.65)$ & $7.22(7.17)$ \\
Total T2 & $7.59(7.13)$ & $8.29(7.68)$ \\
Identity management T1 & $19.05(29.00)$ & $15.38(29.24)$ \\
Identity management T2 & $14.29(22.54)$ & $17.95(25.88)$ \\
Negative expectancies T1 & $13.64(28.47)$ & $12.82(21.68)$ \\
Negative expectancies T2 & $21.21(31.78)$ & $23.08(34.39)$ \\
Negative disclosure experiences T1 & $11.82(21.96)$ & $12.31(22.42)$ \\
Negative disclosure experiences T2 & $8.18(21.08)$ & $12.31(23.86)$ \\
Family rejection T1 & $19.67(30.62)$ & $14.90(25.44)$ \\
Family rejection T2 & $17.44(28.67)$ & $14.34(23.02)$ \\
Internalized homonegativity T1 & $12.49(17.71)$ & $3.30(8.56)$ \\
Internalized homonegativity T2 & $4.16(7.04)$ & $7.69(16.09)$ \\
Homonegative communication T1 & $46.36(32.88)$ & $41.15(25.67)$ \\
Homonegative communication T2 & $42.50(30.15)$ & $47.69(26.51)$ \\
Homonegative climate T1 & $11.36(16.77)$ & $5.77(20.80)$ \\
Homonegative climate T2 & $17.05(28.23)$ & $13.46(26.25)$ \\
Social marginalization T1 & $1.70(4.39)$ & $1.92(4.69)$ \\
Social marginalization T2 & $2.44(6.90)$ & $2.88(5.48)$ \\
Intersectionality T1 & $10.61(26.00)$ & $28.21(40.47)$ \\
Intersectionality T2 & $10.61(23.87)$ & $17.95(32.25)$ \\
Religion T1 & $11.14(16.18)$ & $12.69(17.63)$ \\
Religion T2 & $13.18(19.85)$ & $13.85(18.95)$ \\
Anxiety T1 & $22.08(14.44)$ & $26.89(16.75)$ \\
Anxiety T2 & $19.56(16.08)$ & $27.39(14.14)$ \\
PTSD PCL T1 & $21.81(18.30)$ & $26.78(20.34)$ \\
PTSD PCL T2 & $24.40(19.08)$ & $29.28(17.32)$ \\
Depression (Beck II) T1 & $15.40(11.54)$ & $17.81(9.56)$ \\
Depression (Beck II) T2 & $15.68(11.96)$ & $18.65(12.77)$ \\
Suicide T1 & $0.63(1.31)$ & $0.50(1.34)$ \\
Suicide T2 & $0.71(1.46)$ & $0.61(1.24)$ \\
PTSD 6-item T1 & $13.42(6.00)$ & $15.24(7.15)$ \\
PTSD 6-item T2 & $14.68(6.30)$ & $16.50(5.51)$ \\
\hline & & \\
\hline
\end{tabular}

in depression symptoms. These findings suggest protective effects of the intervention for mental health symptoms among LGBT students. The knowledge youth gained through the stress-based psychoeducation aspect of P\&E broadened their understanding of how minority stress plays a role in the symptoms they experience. This understanding may promote mindful identification and coping with symptoms of stress and anxiety, as found in other studies with adolescents [50]. Furthermore, youth gained peer support through group sharing of common experiences, which has been shown to be related to positive mental health and well-being among SGMA [51]. 
Table 3 Moderated Analyses with SMASI by Intervention Interaction

\begin{tabular}{|c|c|c|}
\hline \multirow[t]{2}{*}{ Predictors } & \multicolumn{2}{|l|}{ Anxiety } \\
\hline & $b$ & $p$ \\
\hline SMASI & 0.14 & 0.730 \\
\hline Intervention & -4.16 & 0.267 \\
\hline Anxiety (T1) & 0.76 & $<0.001$ \\
\hline SMASI x intervention & -0.28 & 0.610 \\
\hline \multirow[t]{2}{*}{ Predictors } & PTSD & \\
\hline & $b$ & $p$ \\
\hline SMASI & 0.81 & 0.063 \\
\hline Intervention & -2.49 & 0.514 \\
\hline PTSD (T1) & 0.76 & $<0.001$ \\
\hline SMASI x intervention & -1.29 & 0.032 \\
\hline Intervention & -0.48 & 0.234 \\
\hline Control & 0.81 & 0.063 \\
\hline \multirow[t]{2}{*}{ Predictors } & Depression & \\
\hline & $b$ & $p$ \\
\hline SMASI & 0.43 & 0.093 \\
\hline Intervention & -1.24 & 0.587 \\
\hline Depression (T1) & 0.96 & $<0.001$ \\
\hline SMASI x intervention & -0.79 & 0.023 \\
\hline Intervention & -0.36 & 0.131 \\
\hline Control & 0.43 & 0.093 \\
\hline \multirow[t]{2}{*}{ Predictors } & Suicidality & \\
\hline & $b$ & $p$ \\
\hline SMASI & 0.07 & 0.087 \\
\hline Intervention & -0.07 & 0.841 \\
\hline Suicidality (T1) & 0.41 & 0.007 \\
\hline SMASI x intervention & -0.14 & 0.012 \\
\hline Intervention & -0.07 & 0.069 \\
\hline Control & 0.07 & 0.087 \\
\hline
\end{tabular}

Finally, we found preliminary evidence that P\&E moderated the relationship between minority stress experiences and mental health symptoms. Analyses identified significant interactions between minority stress experiences and the intervention condition, suggesting that youth in the intervention group were less likely than those in the control group to report elevated PTSD, depression, and suicidality in the face of minority stress experiences. Although we designed P\&E to address many types of proximal experiences of minority stress (e.g., internalized homonegativity, identity management), we recognize that a small group intervention can only go so far to address distal stressors such as homonegative school climates and peer and family rejection. Given that these stressors would be difficult (or impossible) to eliminate with an individualbased intervention, they are likely to be experienced regardless of intervention participation. Thus, we were pleased to see that P\&E appears to provide participants with improved coping skills that may help them in the face of these distal stress experiences. Our findings provide evidence that the intervention moderated the relationship between minority stress and mental health symptoms. That is, even in cases where the intervention may not reduce certain aspects of minority stress, it nevertheless provided youth with tools to cope with those experiences and help prevent subsequent exposure.

Our study is not without limitations. First, we recruited a relatively small sample size in a limited number of schools in one geographic area of the United States. Thus, although some of our findings trended toward significance, we could not detect changes in several of our hypothesized outcome measures, conduct subgroup tests of difference to examine differential impacts (e.g., by race, ethnicity, gender identity), nor look at how school-level structural factors may affect student outcomes. This is a critical challenge of the present study and a subsequent study, with a larger sampling frame, is needed to further understand the relationship between program participation, minority-related stress and behavioral health symptomology. Additionally, recruitment of hard-to-reach youth proved to be successful in this study; nonetheless, we recognize that some youth who are not out to their peers may have been reluctant to participate, and that we may find differing rates of participation in more rural or underserved areas of the United States. Future studies of P\&E should be conducted with larger samples to determine its effectiveness in more geographically diverse areas.

\section{Conclusions}

Despite limitations, this study provides preliminary evidence for the effectiveness of P\&E. The significant findings, despite the relatively small sample size, suggest that the intervention holds promise for reducing experiences of minority stress and mental health symptoms and provides youth with ways to cope with experiences of minority stress. Various reports have identified SGMA as at risk of developing chronic psychopathology and implementing preventive interventions such as P\&E early may be crucial for preventing significant health disparities from developing in the first place.

\section{Abbreviations}

ANOVA: Analyses of Variance; COVID-19: Coronavirus Disease 2019; DSM-5: Diagnostic and Statistical Manual of Mental Disorders, Fifth Edition; HIV: Human Immunodeficiency Virus; LGBT: Lesbian, Gay, Bisexual, and Transgender; LGBTQ: Lesbian, Gay, Bisexual, Transgender and Queer or Questioning; $\mathrm{NIH}$ : National Institutes of Health; P\&E: Proud \& Empowered; PTSD: PostTraumatic Stress Disorder; RCT: Randomized Controlled Trial; SGMA: Sexual 
and Gender Minority Adolescents; SMASI: Sexual Minority Adolescent Stress Inventory.

\section{Acknowledgements}

We acknowledge the hundreds of LGBTQ youth who contributed their time, energy, thoughts and input into creating this intervention, and continuing to push for equity.

\section{Authors' contributions}

$J G, H R, F M$ and PK contributed to the study conception and design. Material preparation and data collection were led by JS. Analysis and reporting of findings were performed by MM. The first draft of the manuscript was written by JG and $H R$, and all authors edited previous versions of the manuscript. All authors read and approved the final manuscript.

\section{Funding}

Research reported in this submission was supported by NIMHD and NICHD of the National Institutes of Health under award numbers 1R21MD013971 and 1R21HD082813. The content is solely the responsibility of the authors and does not necessarily represent the official views of the National Institutes of Health.

ClinicalTrials.gov Registry \#NCT04041414.

\section{Availability of data and materials}

The data can be made available with appropriate IRB approvals by emailing the lead author.

\section{Declarations}

\section{Ethics approval and consent to participate}

The study was reviewed and approved by the USC Social Behavioral IRB. All youth provided signed assent; parental consent was waived by the IRB due to increased risk of disclosure of SOGl to parents.

\section{Consent for publication}

Not applicable.

\section{Competing interests}

None.

\section{Author details}

${ }^{1}$ The Brown School, Washington University in St. Louis, 1 Brookings Dr, MO 63130 St. Louis, USA. ${ }^{2}$ Suzanne Dworak-Peck School of Social Work, University of Southern California, 669 W. 34th St., MRF Bldg, CA 90089-0411 Los Angeles, USA. ${ }^{3}$ The LGBT Community Center, 208 W. 13th St, 10011 New York, NY, USA. ${ }^{4}$ School of Social Work, Arizona State University, 411 N. Central Ave., Suite 720, 85004 Phoenix, AZ, USA.

Received: 1 March 2021 Accepted: 30 November 2021 Published online: 23 December 2021

\section{References}

1. Stettler NM, Katz LF. Minority stress, emotion regulation, and the parenting of sexual-minority youth. J GLBT Fam Stud. 2017;13(4):380-400.

2. Lucassen MF, Stasiak K, Samra R, Frampton CM, Merry SN. Sexual minority youth and depressive symptoms or depressive disorder: A systematic review and meta-analysis of population-based studies. Aust New Zealand J Psychiatry. 2017:51(8):774-87.

3. Jones A, Robinson E, Oginni O, Rahman Q, Rimes KA: Anxiety disorders, gender nonconformity, bullying and self-esteem in sexual minority adolescents: Prospective birth cohort study. J Child Psychol Psychiatry 2017, 58(11):1201-1209

4. Taliaferro LA, Muehlenkamp JJ. Nonsuicidal self-injury and suicidality among sexual minority youth: risk factors and protective connectedness factors. Acad Pediatr. 2017;17(7):715-22.

5. Goldbach JT, Gibbs J. Strategies employed by sexual minority adolescents to cope with minority stress. Psychol Sex Orientat Gend Divers. 2015;2(3):297.
6. Goldbach JT, Mereish EH, Burgess C. Sexual orientation disparities in the use of emerging drugs. Subst Use Misuse. 2017;52(2):265-71.

7. Watson RJ, Goodenow C, Porta C, Adjei J, Saewyc E. Substance use among sexual minorities: has it actually gotten better? Subst Use Misuse. 2018:53(7):1221-8.

8. Smith BC, Armelie AP, Boarts JM, Brazil M, Delahanty DL. PTSD, depression, and substance use in relation to suicidality risk among traumatized minority lesbian, gay, and bisexual youth. Arch Suicide Res. 2016;20(1):80-93.

9. Meyer IH. Prejudice, social stress, and mental health in lesbian, gay, and bisexual populations: conceptual issues and research evidence. Psychol Bull. 2003;129(5):674.

10. Myers W, Turanovic JJ, Lloyd KM, Pratt TC. The victimization of LGBTQ students at school: A meta-analysis. J School Violence. 2020:1-12.

11. Alessi EJ, Martin Jl, Gyamerah A, Meyer IH. Prejudice events and traumatic stress among heterosexuals and lesbians, gay men, and bisexuals. J Aggress Maltreat Trauma. 2013;22(5):510-26.

12. Goldbach JT, Schrager SM, Dunlap SL, Holloway IW. The application of minority stress theory to marijuana use among sexual minority adolescents. Subst Use Misuse. 2015;50(3):366-75.

13. Johns MM, Lowry R, Rasberry CN, Dunville R, Robin L, Pampati S, et al. Violence victimization, substance use, and suicide risk among sexual minority high school students_-United States, 2015-2017. Morb Mortal Wkly Rep. 2018;67(43):1211.

14. Birkett M, Newcomb ME, Mustanski B. Does it get better? A longitudinal analysis of psychological distress and victimization in lesbian, gay, bisexual, transgender, and questioning youth. J Adolesc Health. 2015;56(3):280-5.

15. Pollitt AM, Mallory AB, Fish JN. Homophobic bullying and sexual minority youth alcohol use: Do sex and race/ethnicity matter? Lgbt Health. 2018;5(7):412-20.

16. Goldbach JT, Tanner-Smith EE, Bagwell M, Dunlap S. Minority stress and substance use in sexual minority adolescents: A meta-analysis. Prev Sci. 2014;15(3):350-63.

17. Bouris A, Everett BG, Heath RD, Elsaesser CE, Neilands TB. Effects of victimization and violence on suicidal ideation and behaviors among sexual minority and heterosexual adolescents. LGBT health. 2016;3(2):153-61.

18. Baams L, Dubas JS, Russell ST, Buikema RL, van Aken MA. Minority stress, perceived burdensomeness, and depressive symptoms among sexual minority youth. J Adolesc. 2018;66:9-18.

19. Burton CM, Marshal MP, Chisolm DJ, Sucato GS, Friedman MS. Sexual minority-related victimization as a mediator of mental health disparities in sexual minority youth: A longitudinal analysis. J Youth Adolesc. 2013;42(3):394-402.

20. Teasdale B, Bradley-Engen MS. Adolescent same-sex attraction and mental health: The role of stress and support. J Homosex. 2010;57(2):287-309.

21. Chaudoir SR, Wang K, Pachankis JE. What reduces sexual minority stress? A review of the intervention "toolkit". J Soc Issues. 2017;73(3):586-617.

22. Ryan C. Engaging Families to Support Lesbian, Gay, Bisexual, and Transgender Youth: The Family Acceptance Project. Prev Res. 2010;17(4):11-3.

23. Rice E, Barman-Adhikari A. Internet and social media use as a resource among homeless youth. J Comput-Mediated Commun. 2014;19(2):232-47.

24. Padilla YC, Crisp C, Rew DL. Parental acceptance and illegal drug use among gay, lesbian, and bisexual adolescents: Results from a national survey. Soc Work. 2010;55(3):265-75.

25. Ryan C, Huebner D, Diaz RM, Sanchez J. Family rejection as a predictor of negative health outcomes in white and Latino lesbian, gay, and bisexual young adults. Pediatrics. 2009;123(1):346-52.

26. Craig SL. Affirmative supportive safe and empowering talk (ASSET): Leveraging the strengths and resiliencies of sexual minority youth in school-based groups. J LGBT Issues Couns. 2013;7(4):372-86.

27. Craig SL, Austin A, McInroy LB. School-based groups to support multiethnic sexual minority youth resiliency: Preliminary effectiveness. Child Adolesc Soc Work J. 2014;31(1):87-106.

28. Burk J, Park M, Saewyc EM. A media-based school intervention to reduce sexual orientation prejudice and its relationship to discrimination, bullying, and the mental health of lesbian, gay, and bisexual adolescents in 
western Canada: a population-based evaluation. Int J Environ Res Public Health. 2018;15(11):2447.

29. Onken LS, Carroll KM, Shoham V, Cuthbert BN, Riddle M. Reenvisioning clinical science: Unifying the discipline to improve the public health. Clin Psychol Sci. 2014;2(1):22-34.

30. Goldbach JT, Schrager SM, Mamey MR. Criterion and divergent validity of the sexual minority adolescent stress inventory. Front Psychol. 2017;8:2057.

31. Schrager SM, Goldbach JT, Mamey MR. Development of the Sexual Minority Adolescent Stress Inventory. Front Psychol. 2018;9:319.

32. Caspi A, Moffitt TE, Thornton A, Freedman D, Amell JW, Harrington H, et al. The life history calendar: a research and clinical assessment method for collecting retrospective event-history data. Int J Methods Psychiatr Res. 1996.

33. Schrager SM, \& Goldbach, J. T.: Minority stress measure development: Theoretical concerns and suggested resolutions. Berlin, Germany: Logos Verlag; in press

34. Hershberger SL, Pilkington NW, D'Augelli AR. Predictors of suicide attempts among gay, lesbian, and bisexual youth. J Adolescent Res. 1997:12(4):477-97.

35. Sterzing PR, Gibbs JJ, Gartner RE, Goldbach JT: Bullying Victimization Trajectories for Sexual Minority Adolescents: Stable Victims, Desisters, and Late-Onset Victims. J Res Adolescence 2018, 28(2):368-378.

36. Hatzenbuehler ML, Birkett M, Van Wagenen A, Meyer IH. Protective school climates and reduced risk for suicide ideation in sexual minority youths. Am J Public Health. 2014;104(2):279-86.

37. Goldbach JT, Holleran Steiker LK. An examination of cultural adaptations performed by LGBT-identified youths to a culturally grounded evidence-based substance abuse intervention. J Gay Lesbian Soc Serv. 2011;23(2):188-203.

38. Marshal MP, Dermody SS, Cheong J, Burton CM, Friedman MS, Aranda F, et al. Trajectories of depressive symptoms and suicidality among heterosexual and sexual minority youth. J Youth Adolesc. 2013;42(8):1243-56.

39. Compas BE, Connor-Smith JK, Saltzman H, Thomsen AH, Wadsworth ME. Coping with stress during childhood and adolescence: problems, progress, and potential in theory and research. Psychol Bull. 2001;127(1):87.

40. Goldbach JT, Rho ades, H., Rusow, J., \& Karys, P.: The Development of Proud \& Empowered: An Intervention for Promoting LGBTQ Adolescent Mental Health. Child Psychiatry Hum Dev 2021.

41. Dusenbury L, Brannigan R, Falco M, Hansen WB. A review of research on fidelity of implementation: implications for drug abuse prevention in school settings. Health Educ Res. 2003;18(2):237-56.

42. Castro FGBM, Martinez CR. The cultural adaptation of prevention interventions: Resolving tensions between fidelity and fit. Prev Sci. 2004;5(1):41-5.

43. Cohen S: Social relationships and health American psychologist 2004, 59(8):676.

44. Aycock DM, Hayat MJ, Helvig A, Dunbar SB, Clark PC. Essential considerations in developing attention control groups in behavioral research. Res Nurs Health. 2018:41(3):320-8.

45. Beck AT, Steer R: Beck anxiety inventory (BAI). Überblick über Reliabilitätsund Validitätsbefunde von klinischen und außerklinischen Selbst-und Fremdbeurteilungsverfahren 1988:7.

46. Beck AT, Steer, R. A., \& Brown, G.: Beck Depression Inventory-II [Database record]. In.: APA PsycTests; 1996.

47. Weathers FW, Litz BT, Keane TM, Palmieri PA, Marx BP, Schnurr PP: The ptsd checklist for dsm-5 (pcl-5) Scale available from the National Center for PTSD at www ptsd va gov 2013, 10.

48. Posner K, Brown GK, Stanley B, Brent DA, Yershova KV, Oquendo MA, Currier GW, Melvin GA, Greenhill L, Shen S: The Columbia-Suicide Severity Rating Scale: initial validity and internal consistency findings from three multisite studies with adolescents and adults. Am J Psychiatry 2011 168(12):1266-1277.

49. Hayes AF: PROCESS: A versatile computational tool for observed variable mediation, moderation, and conditional process modeling. In.: University of Kansas, KS; 2012

50. Hampel P, Meier M, Kümmel U. School-based stress management training for adolescents: Longitudinal results from an experimental study. J Youth Adolesc. 2008;37(8):1009-24.
51. Shilo G, Savaya R. Effects of family and friend support on LGB youths' mental health and sexual orientation milestones. Family Relations. 2011;60(3):318-30.

\section{Publisher's Note}

Springer Nature remains neutral with regard to jurisdictional claims in published maps and institutional affiliations.
Ready to submit your research? Choose BMC and benefit from:

- fast, convenient online submission

- thorough peer review by experienced researchers in your field

- rapid publication on acceptance

- support for research data, including large and complex data types

- gold Open Access which fosters wider collaboration and increased citations

- maximum visibility for your research: over 100M website views per year

At BMC, research is always in progress.

Learn more biomedcentral.com/submissions 